Editorial

\title{
Plastic Surgery Specialties in Ayushman Bharat Yojana: The Gaping Concerns
}

\author{
Dinesh Kadam ${ }^{1}$ \\ ${ }^{1}$ Department of Plastic and Reconstructive Surgery, A J Institute of \\ Medical Sciences, A J Hospital and Research Centre, Mangalore, \\ Karnataka, India
}

Indian J Plast Surg 2020;53:1-3

The Ayushman Bharat Yojana is now the frontline health care system of India catering to the most deprived and deserving sections. Nevertheless, the scheme is not without pitfalls. I wish to draw your attention upon why this scheme is tremendously unjust to the specialty of plastic surgery, the needy patients, and why it is self-serving to the other specialties.

\section{Ayushman Bharat HBP 2.0}

In 2017, the government of India announced the National Health Policy with an ambitious goal of Universal Health Coverage (UHC) under the National Health Authority (NHA). It has two interrelated components; Health and Wellness Centers (HWCs) for the primary health care and Pradhan Mantri Jan Arogya Yojana (PM-JAY) for the higher tertiary care. The government of India rolled out Ayushman Bharat Pradhan Mantri Jan Arogya Yojana (AB PM-JAY) in 2018. The aim is to protect weaker economic sections of the society from the burden of health care expenditure. Accordingly, various health benefit packages (HBP) were introduced to cover common health disorders.

The AB PM-JAY dubbed as "Modicare" is the world's largest health insurance/assurance scheme, fully financed by the government. It is expected to benefit more than 500 million people of India by providing up to Rs. 5 lakh annual insurance cover per family. Launched in September 2018, 94 lakhs hospital admissions were covered in 20,104 empanelled hospitals, incurring an expenditure of more than Rs. 10,000 crore until March 2020.

While this is truly a laudable effort, considered as a "game changer" in the health care at face value, it has several pitfalls when analyzed carefully. Insufficient health care budget and involvement of health insurance remain a vital issue. Other problems include unrealistic low package rates, a small number of ailments covered, unequal representation of specialty, improper allotment of procedures in the cross-specialty, and so on. Some of these issues have been discussed many a time by the Indian Medical Association and health care experts. ${ }^{1}$ Addressing some of these issues, the second, improved version HPB 2.0 was launched in December 2019 by the NHA. Currently, it includes 1,573 (previously 1,393 ) medical and surgical conditions from 24 specialties. While efforts to streamline the shortcomings have been made, glaring lapses in specialty recognition continue to persist.

\section{Glaring Gaps}

Specifically, I wish to highlight two glaring omissions concerning plastic surgery specialty:

1. No plastic surgeon was included in the specialists' team when guidelines were formulated.

2. Several procedures are left out from the specialty and arbitrarily handed over to other branches.

\section{No Plastic Surgeon in the 330-Membered Specialist Committee!}

It is abysmal that a plastic surgeon finds no place in the newly constituted scientific committee, which includes 330 specialists from 24 different specialties. ${ }^{2}$ There were none either in the first committee (HBP 1.0, 2018) or in the second (HBP 2.0, 2019). Each specialty was represented with at least 12 to 14 members from their association. The Deputy Chief Executive Officer of the NHA is the authority in constituting this committee, the advisory on all matters on standard treatment workflows (STWs). They recommend on what to include and exclude in HBPs, who should be doing the procedures, what should be the package Dr. Dinesh Kadam MS, DNB,MCh, Professor \& Head, Department of Plastic and Reconstructive Surgery, A J Hospital and Research Centre, Mangalore, Karnataka 575004, India (e-mail: drkadam@yahoo.co.in).
DOI https://doi.org/ $10.1055 / \mathrm{s}-0040-1710144$ ISSN 0970-0358.
(C)2020 Association of Plastic Surgeons of India

published online April 25, 2020
License terms

(우요 $\Theta \circledast$ 
Table 1 Procedure NOT allowed under plastic surgery, but allowed only for other specialties

\begin{tabular}{|c|c|}
\hline Procedure & Primary specialty \\
\hline Polytrauma-Head injury with faciomaxillary injury & OMFS/general surgery/neurosurgery \\
\hline $\begin{array}{l}\text { Polytrauma-Flap cover for compound fracture, emergency tendon, nerve repair and } \\
\text { reconstructive surgery, tendon transfer, tendon reconstruction } \\
\text { Nerve plexus repair and reconstruction, } \\
\text { Nerve plexus injury with vascular repair/grafts }\end{array}$ & $\begin{array}{l}\text { Orthopaedics } \\
\text { Neurosurgery } \\
\text { General surgery }\end{array}$ \\
\hline \# Nasal bone & ENT \\
\hline $\begin{array}{l}\text { Peripheral artery repair } \\
\text { Peripheral bypass artery surgery }\end{array}$ & $\begin{array}{l}\text { Cardiothoracic and vascular surgery } \\
\text { (CTVS) }\end{array}$ \\
\hline $\begin{array}{l}\text { Peripheral nerve repair } \\
\text { Brachial plexus surgery } \\
\text { Cranial nerve (facial nerve) anastomosis } \\
\text { Carpal tunnel release }\end{array}$ & Neurosurgery \\
\hline Nerve repair surgery, ulnar nerve repair, nerve decompression & Orthopaedics \\
\hline Tendon repair, tendon transfer, tenolysis, Duputryens disease, digit amputations & Orthopaedics \\
\hline Tendon transfer & General surgery and orthopaedics \\
\hline Percutaneous \# fixation, ORIF of small bones & Orthopaedics \\
\hline $\begin{array}{l}\text { Mandible reconstruction } \\
\text { Maxilla and mandibular cyst/tumor } \\
\text { Jaw fracture fixation-close/ORIF } \\
\text { Oral submucous fibrosis }\end{array}$ & Oral and maxillofacial surgery (OMFS) \\
\hline $\begin{array}{l}\text { Ptosis, ectropion, entropion, lid repair, lid tumor excision and lid reconstruction, orbit } \\
\text { socket reconstruction }\end{array}$ & Ophthalmology \\
\hline Lip reconstruction-Estlander flap, cheek advancement flap, lip malignancy & General surgery/surgical oncology \\
\hline Flap reconstructive surgery & General surgery/surgical oncology \\
\hline AV fistula, lymphatic excision, lymphedema surgery & General surgery \\
\hline Pinna surgery for trauma/tumor & ENT/surgical oncology \\
\hline Vaginoplasty (Mclndoe technique), VVF/RVF repair & Gynecology \\
\hline All burns-related procedure & Burns surgery \\
\hline
\end{tabular}

\# Denotes fracture.

rate, and other related issues of documentation, FAQs, and so on. The Governing Council of the NHA further ratifies these recommendations before implementation. This scientific committee is the "think tank" of this mammoth scheme and primarily responsible for the quality of the care. This mega team of 330 specialists includes almost every broad and superspecialties, and dental surgery except plastic and reconstructive surgery! The group of specialists unilaterally decided on what procedures a plastic surgeon should and should not do in these packages. In our case, the NHA has violated a fundamental process by not seeking any opinion from the plastic surgery community. All core procedures of plastic surgery have been wrongly claimed under other specialties as their primary specialty to perform. Handling the matter at their whims, the committee has unjustly taken away several routine works of plastic surgery, serving to their own specialty interests. In the environment of rampant cross-specialty encroachment, this is self-serving to those specialties that were at the helm of affair in our absentia.

\section{Specialty Interpretation}

The document published by the NHA defines the procedures of a specialty. It mentions, "Each procedure was examined individually across all specialties, in case similar or same procedure features in other specialties, this procedure was made a Cross Specialty procedure. All relevant specialties were mapped in a single cell against that procedure, separated by comma, thereby ensuring that the procedure can be booked by any of the mapped specialty." The concept and process are acceptable in allowing relevant procedures across different specialties, and this also simplifies digital processing. However, the critical question is, "who decided core procedures of a specialty and on what basis?" The answer obviously is the "constituted specialist" team under NHA, which did not have a single plastic surgeon for this process. The routine procedures of plastic surgery are taken away by the other specialties and claiming as their core procedures. By not granting essential procedures, plastic surgery specialty has been downgraded to a state of "relevant other specialty".

\section{Just Eight Primary Plastic Surgery Packages}

There are only 8 packages for 12 procedures listed exclusively under 'primary specialty' of plastic surgery. Out of these 12 procedures, 3 packages are for tissue expander; 3 for hemangioma; and 1 each for pressure sore, diabetic foot, NPWT, revascularization, pinna reconstruction, and scalp 
Table 2 Procedures listed under "primary specialty" and "cross-specialty"

\begin{tabular}{|c|c|c|c|}
\hline Procedures & Primary specialty & Cross-specialty 1 & Cross specialty 2 \\
\hline Cleft lip/palate & Pediatric surgery & OMFS & Plastic surgery \\
\hline ORIF \#mandible, maxilla, and zygoma & ENT & OMFS & $\begin{array}{l}\text { Plastic surgery } \\
\text { (close reduction, IMF, and \# } \\
\text { nasal bone not included) }\end{array}$ \\
\hline Hypospadias repair & Urology & Paediatric surgery & $\begin{array}{l}\text { Plastic surgery } \\
\text { (follow-up package in urology } \\
\text { only) }\end{array}$ \\
\hline Skin flaps-rotation flaps & General surgery & Surgical oncology & Plastic surgery \\
\hline $\begin{array}{l}\text { Microvascular reconstruction (free flap), } \\
\text { myocutaneous/fasciocutaneous flap, } \\
\text { "rotationplasty" }\end{array}$ & Surgical oncology & Plastic surgery & \\
\hline Split thickness skin graft/Wolfe graft & General surgery & Plastic surgery & Pediatric surgery \\
\hline Vascular reconstruction & Surgical oncology & $\begin{array}{l}\text { Cardiothoracic and } \\
\text { vascular surgery } \\
\text { (CTVS) }\end{array}$ & Plastic surgery \\
\hline
\end{tabular}

\# Denotes fracture.

Note: Plastic surgery is not a primary speciality in many listed core procedures.

avulsion reconstruction. This is ridiculously a minuscule of some procedure, not reflecting day-to-day surgeries of the specialty. The bulk of the procedures are not included in the primary category at all.

The procedures performed by every plastic surgeon such as repair of the injured tendon, nerves, vascular injury, and several reconstructive procedures are missing in the list. Shockingly, in polytrauma, none of the procedures is allowed under plastic surgery (-Table $\mathbf{1}$ ). These procedures are listed primarily under a broad specialty or a different superspecialty. Plastic surgery is considered only as a "relevant crossspecialty" to perform similar procedures of a "primary specialty" (-Table 2). Further, several core procedures have been entirely left out from considering even as a relevant specialty. In cases of polytrauma, for example, a soft tissue cover for the compound fracture is listed under orthopedics. Similarly, faciomaxillary injuries, tendon, and neurovascular injuries, which are operated by us day in, day out, have been excluded altogether from polytrauma. I have compiled both the tables from the list of packages published online by the government. ${ }^{3}$

\section{The Problem and the Cascading Effect}

The AYB-PM JAY scheme is in force across the country at all levels of health care, including tertiary care medical college hospitals where plastic surgery departments exist, and some are functioning for several decades. This glaring anomaly, and perhaps deliberate will have several cascading effects on the quality of patient care, the specialty, the teaching program, and also deprives routine practice for those serving in the private setup. The patients remain the bigger looser when they are denied precious services of an expert.

This arbitration and understating propagates a dangerous trend of cross-specialty encroachment. Any such endorsement by the government machinery could grant legal immunity for such practices. Routine procedures performed by plastic surgeons may themselves need affirmation when challenged legally in future. On the other hand, when unfamiliar procedures are undertaken by other than a relevant specialist, it could be grievous to patients, attracting litigations. Without abdicating, this serious lapse must be rectified immediately along with an appropriate representation of the specialty to the NHA. Real health care benefit cannot be judged by economics alone, but by the quality of care to the neediest.

\section{Conflicts of Interest}

None.

\section{References}

1 Economic Times. IMA points out 'loopholes' in Ayushman Bharat Scheme. https://economictimes.indiatimes.com/news/ politics-and-nation/ima-points-out-loopholes-in-ayushmanbharat-scheme/articleshow/71368185.cms?utm_source=contentofinterest\&utm_medium=text\&utm_campaign=cppst

2 National Health Authority, Government of India. https://www. pmjay.gov.in/sites/default/files/2019-06/Constitution\%20 of\%20Specialist\%20Committees\%20under\%20AB-PMJAY.pdf. Accessed March 21, 2020

3 National Health Authority. https://pmjay.gov.in/sites/default/ files/2020-01/Journey-from-HBP-1.0-to-HBP-2.0.pdf. Accessed March 21, 2020 